\title{
Inter- and intra-annual patterns of Ulva prolifera green tides in the Yellow Sea during 2007-2009, their origin and relationship to the expansion of coastal seaweed aquaculture in China
}

\author{
John K. Keesing ${ }^{\mathrm{a}, \mathrm{b}, *}$, Dongyan Liu ${ }^{\mathrm{b}}$, Peter Fearns ${ }^{\mathrm{c}}$, Rodrigo Garcia ${ }^{\mathrm{a}, \mathrm{c}}$ \\ ${ }^{a}$ CSIRO Wealth from Oceans Flagship, Marine and Atmospheric Research, Private Bag 5, Wembley 6913, Australia \\ ${ }^{\mathrm{b}}$ Yantai Institute of Coastal Zone Research, Chinese Academy of Sciences, Yantai, Shandong 264003, PR China \\ ${ }^{\mathrm{c}}$ Curtin University of Technology, GPO Box U1987, Perth 6845, Australia
}

\section{A R T I C L E I N F O}

\section{Keywords:}

Macroalgal bloom

Green-tide

Ulva

Porphyra aquaculture

Eutrophication

Yellow Sea

\begin{abstract}
A B S T R A C T
The large green-tide events that occurred in the Yellow Sea in $2008\left(3489 \mathrm{~km}^{2}\right)$ and $2009\left(4994 \mathrm{~km}^{2}\right)$ are shown to be novel events preceded only once by a much smaller event in $2007\left(82 \mathrm{~km}^{2}\right)$. The blooms originated in the coastal area of Jiangsu province and spread north-east towards the Shandong Peninsula. The blooms grew at different rates and mesoscale variability in surface winds explained the differences in the spatial and temporal patterns of blooms in 2008 and 2009. The 2009 bloom was tracked to its origin immediately offshore of extensive intertidal flats between Yancheng and Nantong where recent rapid expansion of Porphyra aquaculture has occurred. We review published hypotheses which have been advanced to explain the occurrence of blooms and in light of our findings, we conclude that the accumulation and disposal of waste Ulva prolifera from Porphyra aquaculture rafts is the most likely cause of the blooms.
\end{abstract}

(c) 2011 Elsevier Ltd. All rights reserved.

\section{Introduction}

Some green algae, such as Ulva, Chaetomorpha and Cladophora, can grow inordinately in response to excessive anthropogenically derived nutrients, especially when water temperature conditions are favorable to their growth. This has resulted in the formation of macroalgal blooms and green-tide events in many parts of the world (Fletcher, 1996; Morand and Briand, 1996). Occasionally these events can be large and result in significant environmental damage or socio-economic disruption. The world's largest greentide event occurred in 2008 in Qingdao on the Yellow Sea coast in north-eastern China and aroused attention to the marine environment in China (Liang et al., 2008; Liu et al., 2009). The species responsible was identified as being Enteromorpha prolifera by Wang et al. (2008, 2010), Zhang et al. (2008) and Ding and Luan (2009), using morphological and genetic techniques. Hayden et al. (2003) recently found E. prolifera (O.F. Müller) J. Agardh to be a synonym of Ulva prolifera (O.F. Müller), so from here forward in this paper we refer to the species as $U$. prolifera. Since that time, various news reports and scientific articles have described the event, discussed the causes, evaluated the consequences and stud-

* Corresponding author at: CSIRO Wealth from Oceans Flagship, Marine and Atmospheric Research, Private Bag 5, Wembley 6913, Australia. Tel.: +61 893336500; fax: +61 893336505 .

E-mail address: john.keesing@csiro.au (J.K. Keesing). ied the biology of $U$. prolifera. Fu et al. (2008), Ding et al. (2009), Leliaert et al. (2009), Li et al. (2009), Liu et al. (2010a,b) and Pang et al. (2010) studied aspects of its biology and genetics. The scale of the bloom and its movement was described using satellite tracking methods by $\mathrm{Hu}$ and $\mathrm{He}$ (2008), Hu (2009), Liu et al. (2009), Shi and Wang (2009) and Hu et al. (2010). A variety of possible causes were advanced by Liu et al. (2009), Ding et al. (2009), Pang et al. (2010), Xu et al. (2009), Zhang et al. (2010) and Hu et al. (2010). Liu et al. (2009) predicted that blooms would recur annually and Liu et al. (2010a) have described the subsequent 2009 green-tide event, which was similar in magnitude to that in 2008. Both blooms resulted in very large green-tide events with masses of algae washing ashore on the Shandong Peninsula in June 2008 and July 2009 with 1 million tonnes of algae being removed from the beaches and shoreline during the cleanup in Qingdao in 2008 (Liu et al., 2009; Shi and Wang, 2009). Liu et al. (2010a) used molecular methods to match the homology of the algae washed up on the shore in Qingdao in 2008 with that collected from Porphyra aquaculture rafts from Jiangsu province coastline in the southern Yellow Sea and more recently Liu et al. (2010b) found there was no evidence of the strain of $U$. prolifera responsible for the blooms being present in Qingdao at other times of the year confirming a distant source of the algae responsible for the 2008 green tide. Liu et al. (2009, 2010a) and Hu et al. (2010) attributed the cause of both blooms to the recent expansion of coastal Porphyra yezoensis seaweed culture along the Jiangsu province coast- 
line citing the high biomass of waste $U$. prolifera that grows on the Porphyra aquaculture rafts as the source biomass for the bloom. Some scientists attributed the source of the 2008 U. prolifera bloom to the Yangtze River (Xu et al., 2009) and the eutrophic condition of the Yellow Sea (Leliaert et al., 2009) which is influenced by outflows from the Yangtze River (e.g., Wang et al., 2003). Zhang et al. (2010) suggested somatic cells in marine sediments provided a propagule bank for U. prolifera. Pang et al. (2010) also compared the genetics of $U$. prolifera in the 2008 Qingdao green tide with that from other coastal locations in Jiangsu province and attributed the 2008 bloom to a supply of $U$. prolifera thalli and germlings in the effluent of onshore aquaculture ponds used for shrimp and crab aquaculture. Ding et al. (2009) concluded either aquaculture ponds or Porphyra aquaculture could be responsible for the seed biomass for the bloom. One source of uncertainty contributing to the multitude of hypotheses about the source of the blooms is a lack of accurate determination of the locality of origin of the blooms, hence this was one of the objectives of this study.

One point of agreement seems to be that the recent large-scale $U$. prolifera blooms in the Yellow Sea are novel events, although $\mathrm{Hu}$ et al. (2010) attributed a large bloom detected by remote sensing in 2008 in the East China Sea to macroalgae and suggested they could have the same source as the more recent blooms in the Yellow Sea.
However, the premise that the 2008 bloom was novel is based on the absence of reports of large-scale green-tides washing ashore on the north-east coastline although news reports of a small scale green tide occurring in 2007 exist (Jiang et al., 2008; Ding et al., 2009; Liu et al., 2009). While it is unlikely that large-scale greentide events could have gone un-noticed, it is possible that largescale blooms that did not wash ashore could have occurred in the Yellow Sea before 2008.

Thus, the objectives of this study were to: (1) determine the novelty of the bloom that lead to the 2008 Yellow Sea green-tide; (2) examine the oceanographic influences on the evolution of the 2008 and 2009 green tides and (3) track the origin of blooms and consider the relevance of this to hypotheses proposed by Liu et al. (2009), Xu et al. (2009) and Pang et al. (2010) which nominate different point sources to explain the cause of the blooms.

\section{Methods}

In order to determine the novelty and location of origin of the bloom we used satellite remote sensing methods. Daily Moderate Resolution Imaging Spectroradiometer (MODIS) Aqua and Terra satellite images (http://oceancolor.gsfc.nasa.gov) of $250 \mathrm{~m}^{2}$ resolution

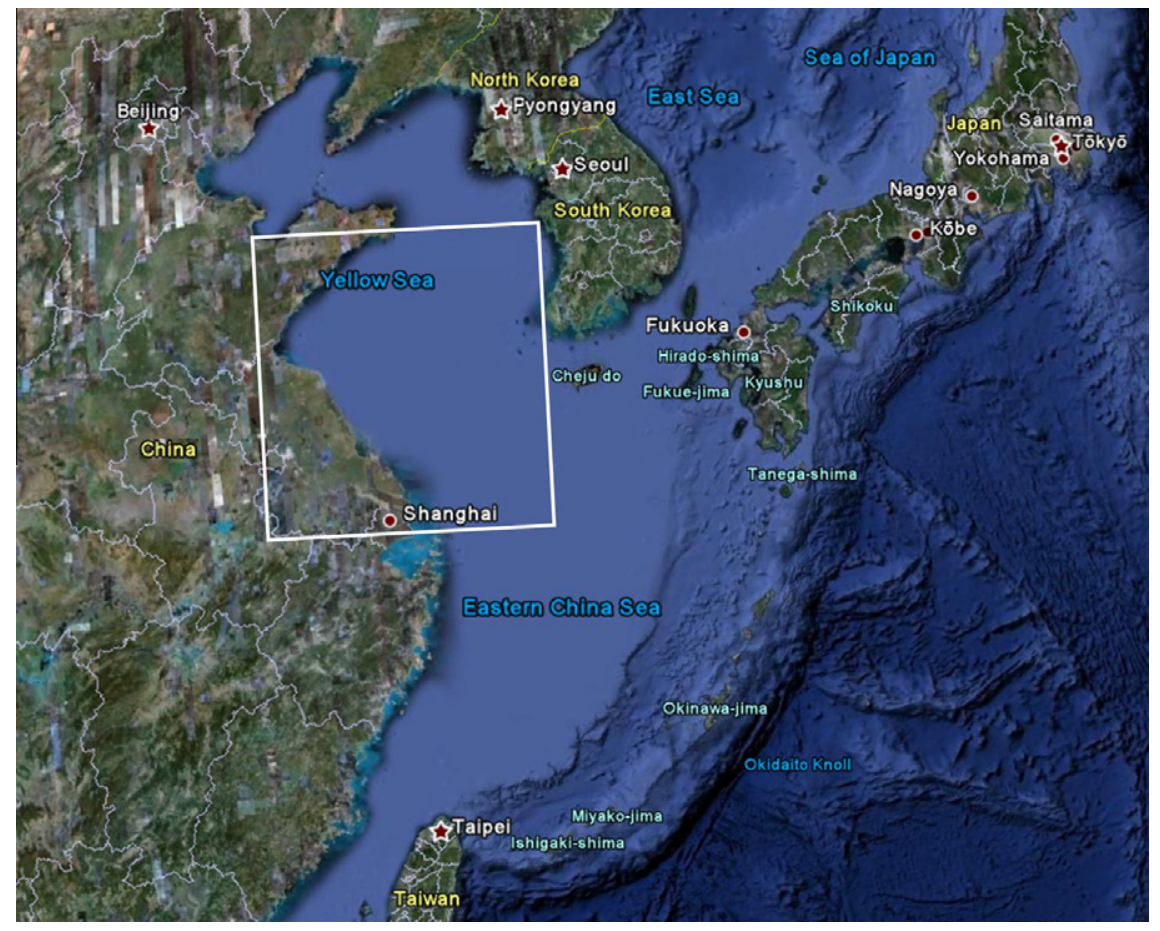

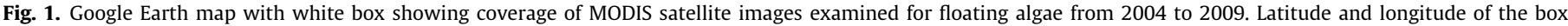
corners are given in the text.

Table 1

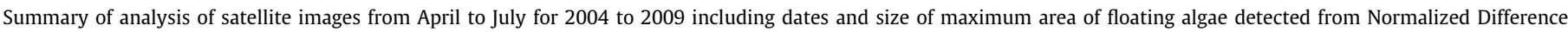
Vegetation Index (NDVI).

\begin{tabular}{|c|c|c|c|c|c|}
\hline Year & $\begin{array}{l}\text { Total (April, May, June, July) } \\
\text { sufficiently cloud free days }\end{array}$ & Days with floating algae & $\begin{array}{l}\text { Date of day with highest } \\
\text { number of pixels with } \\
\text { floating algae }\end{array}$ & $\begin{array}{l}\text { Area of pixels with floating } \\
\text { algae on day with highest } \\
\text { area of floating algae }\left(\mathrm{km}^{2}\right)\end{array}$ & $\begin{array}{l}\text { Extent or spread of floating } \\
\text { algae on day with highest area } \\
\text { of floating algae }\left(\mathrm{km}^{2}\right)\end{array}$ \\
\hline 2004 & $18(7,5,4,2)$ & 0 & - & & \\
\hline 2005 & $15(6,6,3,0)$ & 0 & - & & \\
\hline 2006 & $7(4,1,1,1)$ & 0 & - & & \\
\hline 2007 & $14(6,5,0,3)$ & $1(0,0,0,1)$ & 17 July & 82.3 & 10,638 \\
\hline 2008 & $19(4,7,3,5)$ & $12(0,6,3,3)$ & 31 May & 3488.7 & 84,109 \\
\hline 2009 & $26(7,11,7,2)$ & $13(0,5,7,2)$ & 15 July & 4993.9 & 70,382 \\
\hline
\end{tabular}


were obtained for the Yellow Sea (area bounded by latitudes $31^{\circ} \mathrm{N}$ and $37^{\circ} \mathrm{N}$ and longitudes $119^{\circ} \mathrm{E}$ and $126^{\circ} \mathrm{E}$, see Fig. 1) from 1 April to 31 July for each year from 2004 to 2009 . These images were examined using the method described below to search for days that were sufficiently cloud free to observe floating patches of algae if they existed at the time. Satellite images from August were also searched, but only for the years where floating algae appeared in July. Images from the Yellow Sea region were occluded by cloud for significant periods during the summer period making it impossible to examine continuously for evidence of floating algae. Fortunately, the floating algae are persistent when present, meaning just a few sufficiently cloud free days each month were sufficient to identify the incidence of algal blooms using MODIS images.

We developed a new, yet simple algorithm for floating algae detection utilizing MODIS images. This approach generates a product we term the Scaled Algae Index (SAI) and is similar to the approaches developed by Shi and Wang (2009) and Hu (2009), but utilizes top of atmosphere (TOA) radiances instead of TOA or surface reflectances. We found our method to be robust and well suited to detecting floating algae in the highly variable atmospheric, turbid water and sun-glint affected conditions encountered in the MODIS scenes in this study. A vegetation index akin to the terrestrial Normalized Difference Vegetation Index (NDVI) (Rouse et al., 1974) is calculated and used to classify individual pixels as either containing floating algae or not containing floating algae. Application of standard atmospheric correction procedures to MODIS scenes proved problematic. The atmospheric conditions of the Yellow Sea region encountered in this work proved highly variable and quite turbid, and the ocean reflectance ranged from typical dark ocean pixels to extremely bright coastal waters. Sun-glint was also a significant issue in a number of scenes. Consequently, distinguishing floating macroalgae by applying a single scene-wide NDVI threshold is not possible without accurate and robust corrections for these atmospheric, turbid water and sun-glint effects. Our approach to calculating a vegetation index was to determine a background ocean signal for specific localized regions then subtract this from the pixel-of-interest to produce an SAI, thereby scaling all non-algae pixels to values close to zero, and enhancing the contrast between floating algae and the surrounding ocean. The detail of this method will be described elsewhere but can be summarized as follows. We computed the NDVI for the entire region of the Yellow Sea, using the radiances at the red $(645 \mathrm{~nm})$ and nearinfrared ( $859 \mathrm{~nm}$ ) bands of MODIS. All images were navigated to a standard $250-\mathrm{m}$ spatial grid using a cylindrical equidistant projection. A land mask and a cloud mask were applied to the scenes. For the cloud mask, we employed the $2130 \mathrm{~nm}$ band over open ocean pixels and the $7325 \mathrm{~nm}$ band over highly turbid coastal waters to discriminate cloud.

For each image pixel, we calculated the median NDVI value for a square box region of $25 \times 25$ pixels centered on the pixel-of-interest and calculated the SAI by subtracting this median value from the central pixel. We then classified all pixels in the SAI image above a specific threshold value as "algae" and all values below the threshold as 'non-algae'. The threshold was determined by analyzing the distribution of SAI values for a number of clear ocean regions in the SAI image. Extensive testing (details not shown here) led us to select a threshold equal to 3.5 standard deviations above the mean (i.e. $\mu+3.5 \sigma$ ). This threshold accounts for more than $99.9 \%$ of ocean pixels within the clear ocean regions. We assume that any algae-affected pixels, if they were present, would display an SAI higher than this threshold. Indeed, although the classification of algae pixels is sensitive to box size region, we found through thorough sensitivity analysis that the $25 \times 25$ pixel box size was optimal and classified the majority of NDVI floating algae pixels as "algae" and minimized false classification of ocean pixels as "algae".
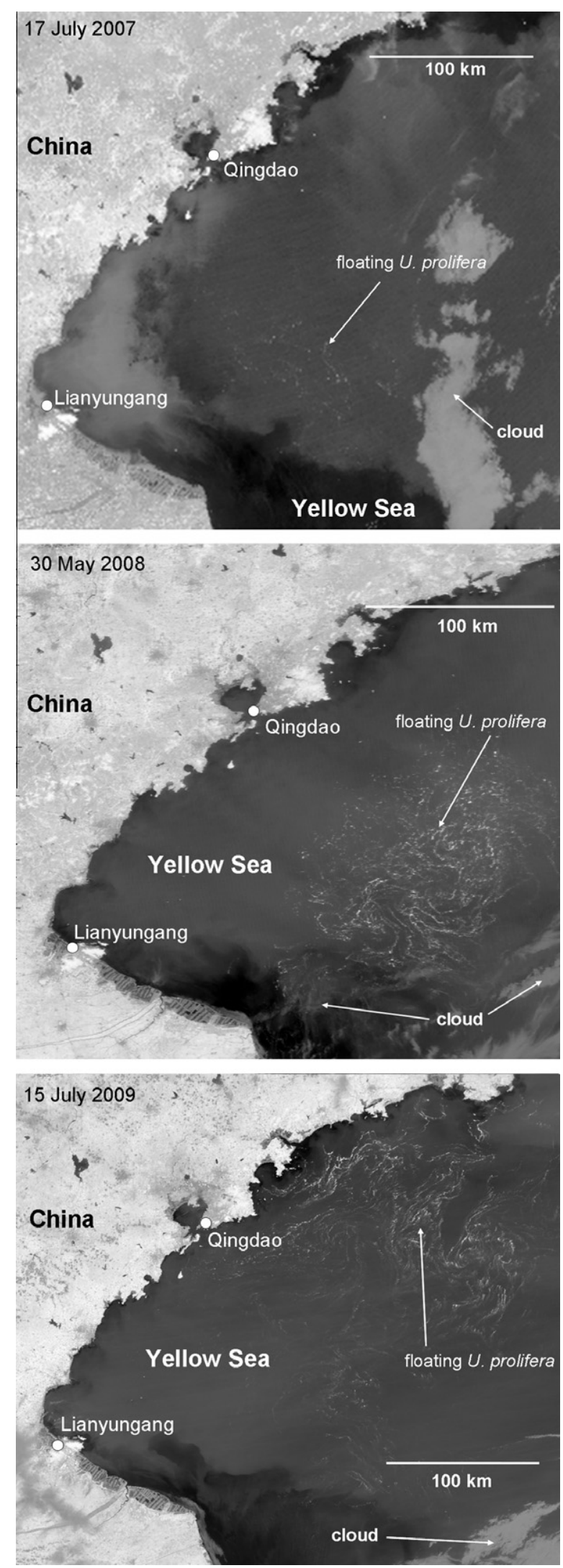

Fig. 2. NDVI images at or near* the peak period of floating algae detected in each year from 2007 to 2009. No floating algae were observed in NDVI images from 2004 to 2006. *31 May 2008 had the peak area of floating algae but the image for 30 May is shown here as it has greater contrast. The areas were similar on both days.

Two areal extents of algae were calculated, the extent of the area affected and the actual area of coverage of algae. The actual 
area of coverage is equal to the number of pixels containing an SAI at least 3.5 standard deviations above background threshold values multiplied by the individual pixel size $(250 \mathrm{~m} \times 250 \mathrm{~m})$. The extent of the area affected is equal to the smallest geographic area that can be drawn to contain all pixels of floating algae above the threshold. This area was calculated by determining the convex hull (Cormen et al., 2001), the smallest possible enclosing convex polygon around the patches of floating algae. A combination of the two areas can provide an estimate of the percentage of area affected (algae cover divided by convex hull).

We used the time sequence of SAI processed images to track the origin of each of the annual blooms back to the location of their first observation and then oceanographic features were used to infer the likely pattern of growth and movement prior to first observation. To compare the patterns of floating algae with oceanographic features, we chose to examine wind and sea surface temperature (SST) for the years that we observed the floating algae and for the two years prior to the first observation of floating algae. In the Yellow Sea, the summer surface currents are known to be wind driven (Naimie et al., 2001; Liu and $\mathrm{Hu}, 2009$ ). Monthly and weekly remotely sensed wind data were obtained from QuikSCAT data archives (Remote Sensing Systems in Santa Rosa, California, USA, http://www.ssmi.com/qscat/). Monthly averaged night-time
SST data for April, May, June and July were obtained from the NASA data distribution system (http://oceancolor.gsfc.nasa.gov).

\section{Results}

3.1. Inter-annual variability in the occurrence of floating algae as observed from satellite ocean color

Based on the analysis of satellite images from 2004 to 2009, we found the earliest evidence of floating algae in the Yellow Sea occurred in 2007. Floating algae were observed only in the years of 2007 (1 day), 2008 (12 days) and 2009 (13 days) (Table 1). The peak days of floating algae observed were in July in 2007 and 2009 and in May in 2008 (Fig. 2). Only one image showing floating algae was found in 2007 due to excessive cloud cover. The area covered by floating algae in 2007 was $82 \mathrm{~km}^{2}$ (spread over $\left.10,638 \mathrm{~km}^{2}\right)$ compared with $3489 \mathrm{~km}^{2}\left(84,109 \mathrm{~km}^{2}\right)$ in 2008 and $4994 \mathrm{~km}^{2}\left(70,382 \mathrm{~km}^{2}\right)$ in 2009 (Table 1). There was no evidence of any floating algae from 2004 to 2006 (Table 1). It should be noted that 2006, with just seven cloud free days between April and June, was the only year where cloud cover restricted the search for floating algae on satellite images. All other years had between
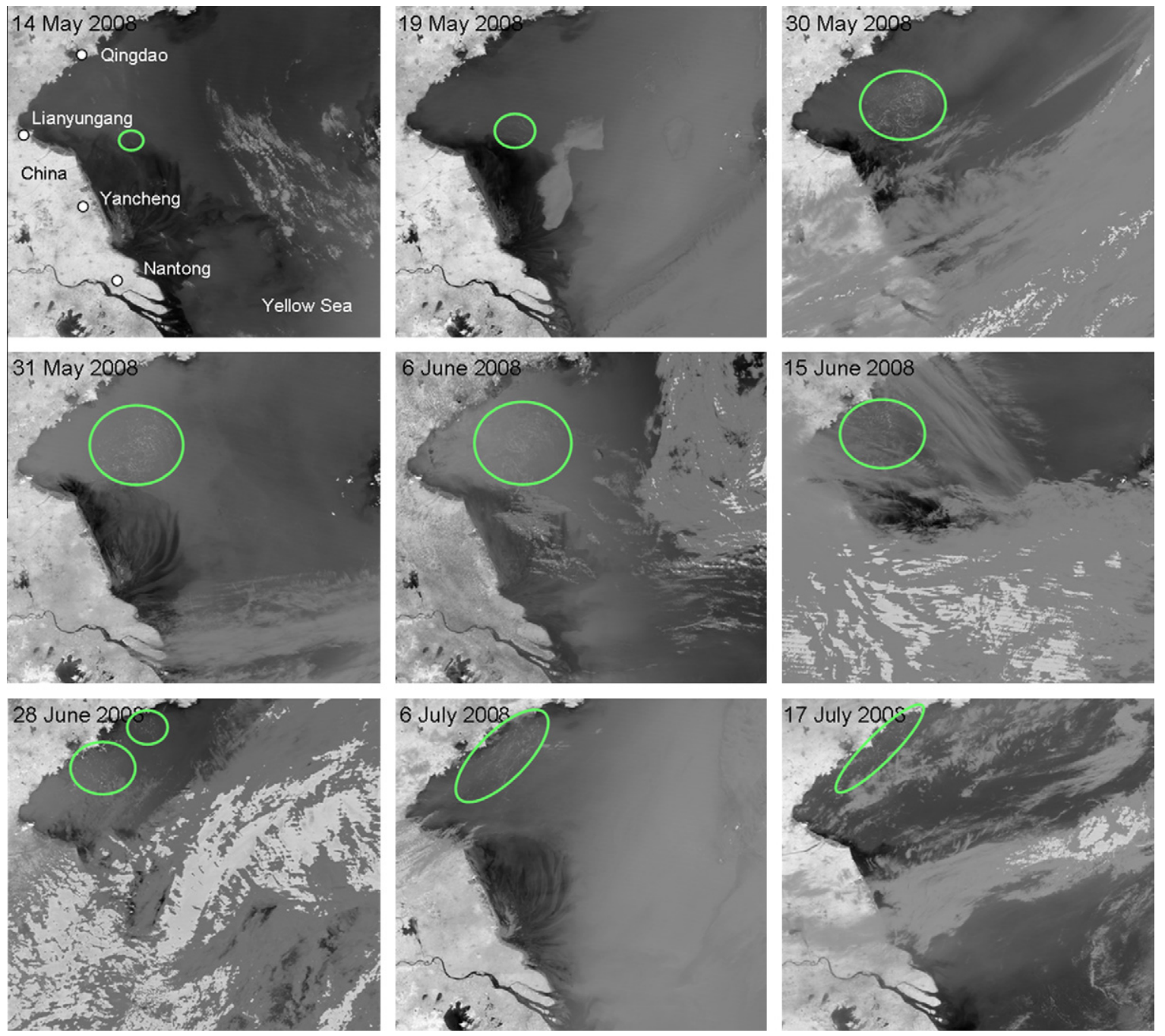

Fig. 3. NDVI images of floating algae detected in 2008. Circles and ellipses denote extent of floating algae. 
14 and 26 days that were cloud free or sufficiently cloud free to observe the sea surface (Table 1 ).

\subsection{Comparison of 2008 and 2009 blooms and intra-annual bloom dynamics}

In contrast to 2007, there were sufficient satellite images to permit a time series comparison of the blooms in 2008 and 2009. Both blooms were first observed in May but the greater size and spread of the 2008 bloom when first visible, suggests it had formed some time earlier relative to the 2009 bloom. In 2008, the bloom was first visible at $\left(34^{\circ} 30^{\prime} \mathrm{N} 121^{\circ} 15^{\prime} \mathrm{E}\right), 90 \mathrm{~km}$ north-north-east of the prominent point south-east of Lianyungang on the 15 May (Fig. 3), and covered $146 \mathrm{~km}^{2}$ spread over $7035 \mathrm{~km}^{2}$ (Table 2). In 2009 , a smaller bloom $\left(119 \mathrm{~km}^{2}\right)$ in the form of at least three lines about $25 \mathrm{~km}$ long was first visible on May 26 at $33^{\circ} 02^{\prime} \mathrm{N} 121^{\circ} 45^{\prime} \mathrm{E}$ (Fig. 4 and Table 2) $77 \mathrm{~km}$ east of the coast near Yancheng and $170 \mathrm{~km}$ to the south of where the 2008 bloom was first observed. Both blooms grew to cover a large area in both the area of the bloom and the extent of the sea affected (Table 2) and both moved to the north as they grew (Figs. 3 and 4). In contrast, the 2008 bloom developed faster than that in 2009. The 2008 bloom reached its peak size of $3489 \mathrm{~km}^{2}$ spread over $84,109 \mathrm{~km}^{2}$ on 31 May (Table 2), 16 days after it was first observed on 15 May. Between 15 May and 31 May, the bloom grew at a rate of $209 \mathrm{~km}^{2}$ or $21.9 \%$ per day. The 2009 bloom reached its peak size of $4994 \mathrm{~km}^{2}$ spread over $70,382 \mathrm{~km}^{2}$ on 15 July (Table 2), 50 days after it was first observed, a growth rate of $98 \mathrm{~km}^{2}$ or $7.7 \%$ per day.

In comparison, the impact of the 2009 bloom was far more widespread than that in 2008. On 15 June 2008, the bloom can

\section{Table 2}

Area of floating algae detected in selected NDVI images from 2007 to 2009. Areas for all days illustrated in Figs. 3 and 4 could not be calculated accurately because of interferences of cloud coverage over part of the bloom area. *Terra MODIS imagery, +threshold increased to 5.0 standard deviations from the mean, ${ }^{++} 6.0$ standard deviations. The standard threshold of $3.5 \sigma$, although sufficient in isolating floating algae in most open ocean situations, can result in the appearance of artefacts when applied to coastal regions, such as during 26, 28 and 31 May 2009. For these three dates, a threshold of $5.0 \sigma$ from the mean effectively removed any 'non-algae' pixels. What appeared to be image "noise" was also observed for the 15 May 2008. For this date a threshold of $6.0 \sigma$ from the mean was chosen. Note also that the area covered by floating algae estimated from Terra satellite images also includes contamination from sensor-induced striping. Simply increasing the threshold to remove these artefacts will also remove significant amounts of floating algae pixels, resulting in severe underestimations of areal coverage. On average, image striping constitutes approximately $1 \%$ of the pixels in any given area of the image. Thus, the effect of striping was removed by subtracting $1 \%$ from the percent coverage, that is, the percentage ratio of the floating algae coverage divided by the area affected by floating algae. For example, for the 17 July 2008 , the percent coverage was estimated at $5.42 \%$, however correcting this figure by $1 \%$ reduces the percent coverage of floating algae to $4.42 \%$.

\begin{tabular}{lcc}
\hline Date & $\begin{array}{l}\text { Area of pixels } \\
\text { with floating } \\
\text { algae }\left(\mathrm{km}^{2}\right)\end{array}$ & $\begin{array}{l}\text { Extent or area } \\
\text { affected by floating } \\
\text { algae }\left(\mathrm{km}^{2}\right)\end{array}$ \\
\hline 17 July 2007 & 82.3 & 10,638 \\
15 May 2008 & 7035.2 \\
20 May 2008 & 145.9 & 7863.2 \\
30 May 2008 & 534 & 20218.4 \\
31 May 2008* & 3475 & 84,109 \\
5 June 2008 & 3488.7 & 20167.7 \\
28 June 2008 & 2156.6 & 29749.6 \\
6 July 2008* & 2081.7 & 53620.2 \\
17 July 2008* & 2547.8 & 15394.3 \\
4 August 2008 & 834.1 & 34873.9 \\
26 May 2009 & 437.6 & 6348.6 \\
28 May 2009 & 119.3 & 10939.6 \\
31 May 2009*,+ & 170.9 & 14586.2 \\
22 June 2009 & 353.3 & 34332.4 \\
24 June 2009 & 2592.4 & 73611.4 \\
1 July 2009 & 3262.4 & 52744.3 \\
15 July 2009 & 4435.8 & 70381.6 \\
14 August 2009 & 4993.9 & 21735.8 \\
\hline
\end{tabular}

be seen moving north-west and approaching the coastline near Qingdao (Fig. 3). On 28 June 2008, 28 days after its peak, the bloom can be seen clearly in contact with the coast along a section $185 \mathrm{~km}$ in length between Rushan in the north and in between Qingdao and Rizhao in the south (Fig. 3). Then, a large amount of algae can still be seen floating offshore of the Shandong Peninsula 19 days later on 17 July. At this time it covered $834 \mathrm{~km}^{2}$ and was spread along $140 \mathrm{~km}$ of coastline. The bloom remained visible until 4 August 2008 when it covered $438 \mathrm{~km}^{2}$ (Table 2 and Fig. 3). In contrast, the 2009 bloom made contact with the coastline closer to the time of its peak size. Fig. 4 shows that on 1 July 2009 the bloom covered $4436 \mathrm{~km}^{2}$ spread over $52,744 \mathrm{~km}^{2}$ with algae stretched $300 \mathrm{~km}$ in a north-east direction. By 15 July 2009, the bloom had reached its peak size and can be seen close to the coast spread along the coastal area between Qingdao in the south and to the end of the Shandong Peninsula in the north, a distance of $245 \mathrm{~km}$ (Fig. 4). As in 2008, the 2009 bloom was persistent offshore with large amounts of algae still visible offshore and along the coast on 9 August and 14 August $\left(574 \mathrm{~km}^{2}\right)$ affecting areas as far south as Rizhao (Fig. 4 and Table 2).

\subsection{Inter- and intra-annual patterns of monthly averaged SST in the} Yellow Sea between 2005 and 2009

Sea surface temperature (SST) in the central-western Yellow Sea showed a general degree of consistency within months between years (Fig. 5). Temperatures in April range between 6 and $12^{\circ} \mathrm{C}$ with a gradient of cooler water in the north near the Shandong Peninsula and warmer in the south near Shanghai. In May, temperatures were warmer ranging from 10 to $18^{\circ} \mathrm{C}$, mostly 12 to $16^{\circ} \mathrm{C}$, while coastal waters are warmer than offshore In general, the waters in the north were cooler than in the south. Temperatures warmed further in June and July, ranging from 15 to $24^{\circ} \mathrm{C}$ in June and 20 to $28{ }^{\circ} \mathrm{C}$ (mostly 22 to $26^{\circ} \mathrm{C}$ ) in July. The north-south temperature gradient was still evident in June and July in most years but was much weaker than in April and May. There was some variability between years especially in May and June. Both 2006 and 2009 were notably warmer years with modal temperatures along the central Jiangsu province coast of $16-18^{\circ} \mathrm{C}$ (May) and 22$24{ }^{\circ} \mathrm{C}$ (June) while 2008 was the coolest May and June with modal temperatures of $12-14{ }^{\circ} \mathrm{C}$ and $18-22^{\circ} \mathrm{C}$, respectively. The locations of the floating patches of green algae superimposed on the SST maps (Fig. 5) do not indicate any clear pattern of association with water temperature.

\subsection{Inter- and intra-annual patterns of monthly averaged winds in the Yellow Sea between 2005 and 2009}

Surface winds are the predominant influence on currents in the Yellow Sea during summer (Naimie et al., 2001; Liu and Hu, 2009). The surface winds for the April to July period from 2005 to 2009 are shown in Fig. 6. A number of features are evident. Firstly, during this period in all years winds are light, between 5 and $10 \mathrm{~m} \mathrm{~s}^{-1}$ and mostly between about 5 and $8 \mathrm{~m} \mathrm{~s}^{-1}$ (10-15 knots) and with very little variability between months and between years over the region of interest in the central-western Yellow Sea. Secondly, during the months of May through July, winds are predominantly from the south and south-east meaning surface currents flowed in a predominantly northward direction. However, there are some differences between years. Two sets of different wind patterns were between May 2007/2008 and 2009 when the wind near Shandong Peninsula was more westerly in 2009 (Fig. 6) and between June 2007/2008 and June 2006/2009 when the wind near Shandong was more easterly in June 2006 and 2009 (Fig. 6). These differences were examined in more detail by comparing weekly 

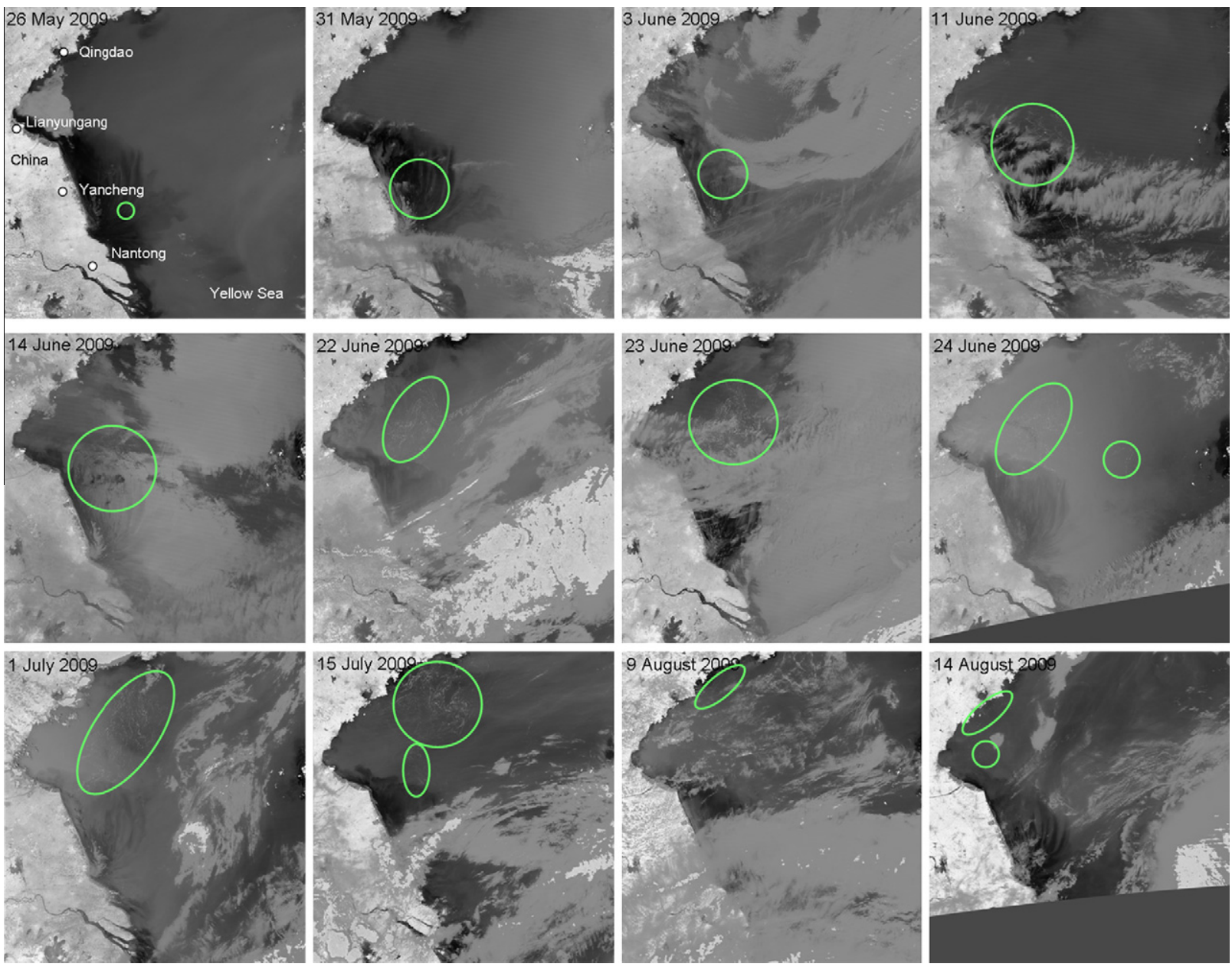

Fig. 4. NDVI images of floating algae detected in 2009. Circles and ellipses denote extent of floating algae.

averages for winds in these months from 2007 to 2009 and comparing them to patterns of floating algae in these years.

Wind direction in April is more variable than in later spring and summer months with a stronger westerly component evident in the eastern Yellow Sea in all years except 2005 but in the central-western Yellow Sea wind direction was still predominantly from the south and south-east. A wind gyre in the Yellow Sea with varying position is evident in April in 2006, 2007, 2008 and 2009 but not 2005 (Fig. 6).

3.5. Relationship between patterns of monthly and weekly averaged winds and movement of algal blooms in the Yellow Sea between 2007 and 2009

Throughout May 2008 where the floating algae were observed the winds were consistently blowing to the north and to the north-west at about 5-8 $\mathrm{m} \mathrm{s}^{-1}$ (Figs. 6 and 7a) while during May 2009 winds were lighter $5-8 \mathrm{~m} \mathrm{~s}^{-1}$ and while mostly northwards, included periods of southward and north-east movement. May 2007 was similar to 2008 except for a short period of winds to the north-east (Fig. 7a). The movement of the floating algae during May 2008 northward was highly consistent with that of the winds in that period. Floating algae were not observed in May 2007 and only very late in May 2009 (Fig. 7a).

During June 2008, winds in the area that affected floating algae were predominantly towards the west or north-west (Fig. 7b). This corresponds with the period of transport of the bloom westwards and onto the coast near Qingdao. Winds in early to mid July
2008 were towards the north (Fig. 7b and c) keeping the bloom onshore as shown in the NDVI images (Fig. 3). June 2009 was the period of most active growth of the bloom (Fig. 4) and the winds during June were consistently towards the north (Fig. 7b) corresponding with the position and movement of the algae during this period (Fig. 4). Between 24 June and 1 July, the bloom spread significantly to the north-east. This corresponded closely with winds to the north-east during this period (Fig. 7b). In the following week, winds shifted back towards the north-west and increased (Fig. 7c) and this corresponded with the onshore movement of the algae between 1 and 15 July (Fig. 4). Winds in August also mirror the movement of the algae onshore along the northern Shandong Peninsula on August 9 (Fig. 7c) and then south-west towards, and to the south of Qingdao on August 14 (Fig. 7c).

\subsection{Location of origin of blooms in 2007-2009}

The close relationship between temporal patterns in surface winds and the movement of floating algae in the Yellow Sea can be used to infer the location of origin of the blooms and in particular the source of the $U$. prolifera bloom seed biomass. Of all three blooms detected, the 2009 bloom was able to be tracked from its smallest size $\left(119 \mathrm{~km}^{2}\right)$ (Table 2 and Fig. 4). The 2009 bloom was tracked to a series of long chains (ca. $25 \mathrm{~km}$ ) centered on $33^{\circ} 02^{\prime} \mathrm{N} 121^{\circ} 45^{\prime} \mathrm{E}, 77 \mathrm{~km}$ off the coast between Yancheng and Nantong (Fig. 8c). Algae in the 26 May 2009 image can be seen as close as $60 \mathrm{~km}$ to the shore. Winds in the 10 days prior to this were from the south-west meaning the algae could have originated from near 

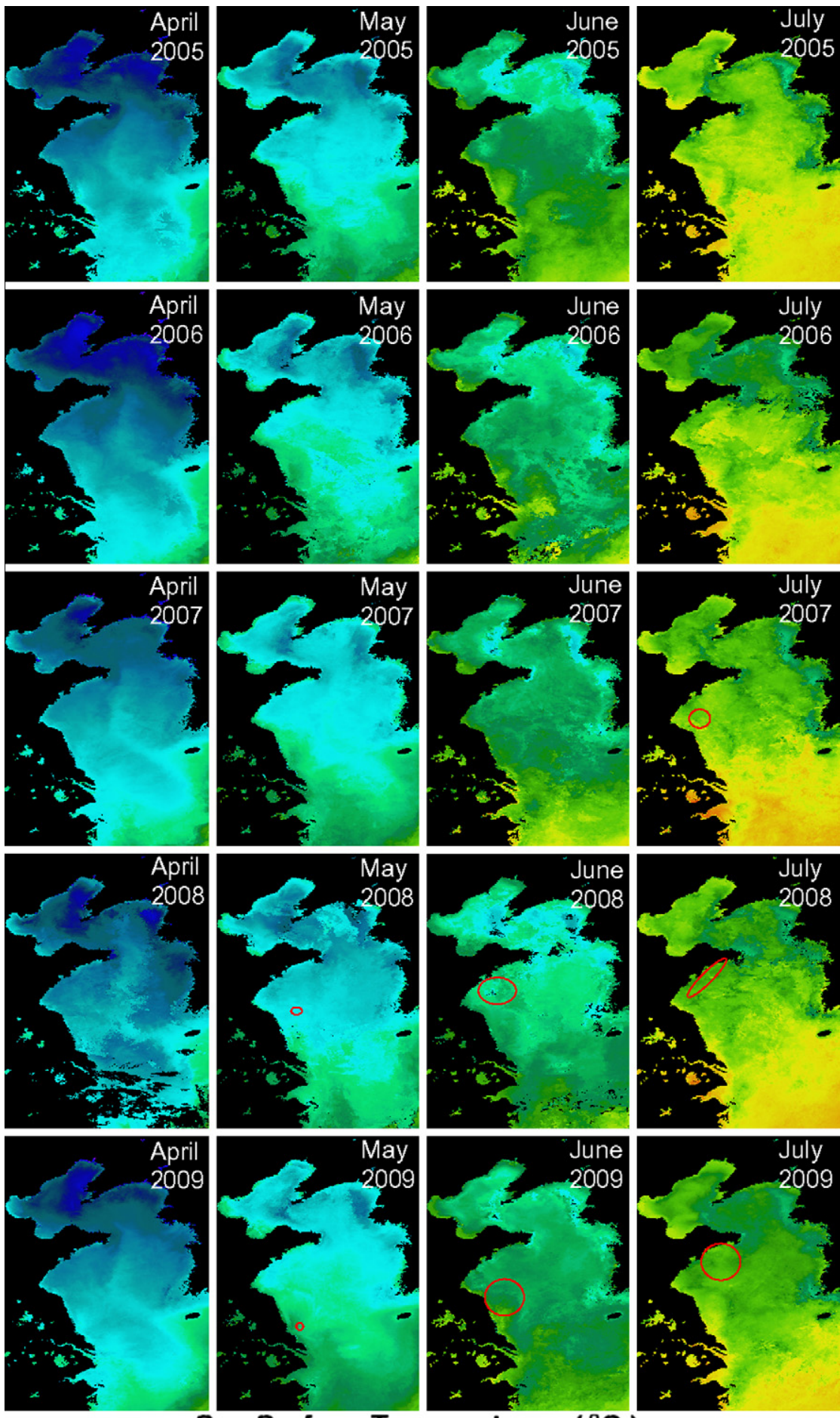

Sea Surface Temperature $\left({ }^{\circ} \mathrm{C}\right)$

$\begin{array}{llllllllllllllllllllllllllll}-2 & 0 & 2 & 4 & 6 & 8 & 10 & 12 & 14 & 16 & 18 & 20 & 22 & 24 & 26 & 28 & 30 & 32 & 34 & 36 & 38 & 40 & 42 & 44\end{array}$

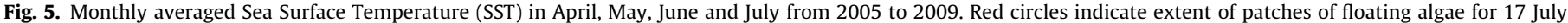
2007, 14 May 2008, 15 June 2008, 17 July 2008, 26 May 2009, 14 June 2009 and 15 July 2009.

to the shore slightly to the south of its observed position on 26 May 2009. The tidal range recorded nearby at Shanghai at this time exceeded $3.5 \mathrm{~m}$ and had exceeded $1.3 \mathrm{~m}$ for all the previous week meaning that a combination of tide and wind action most likely brought the algae offshore to its location recorded on 26 May 2009.

The 2008 bloom was first detected in an area centered $90 \mathrm{~km}$ off the Lianyungang coastline at a size of $146 \mathrm{~km}^{2}$ spread over
$7035 \mathrm{~km}^{2}$ (Fig. 3 and Table 2). Algae in the 19 May 2008 image can be seen as little as $60 \mathrm{~km}$ off the coast (Fig. $8 \mathrm{~b}$ ). At this point it was offshore of extensive coastal aquaculture ponds (Fig. 8b), however its relatively larger size and spread suggests it was much older than the 2009 bloom when first detected. Wind data from May 2008 suggest the 2008 bloom would have been initiated to the south of where it was first observed on 15 May 2008 (Fig. 3). 


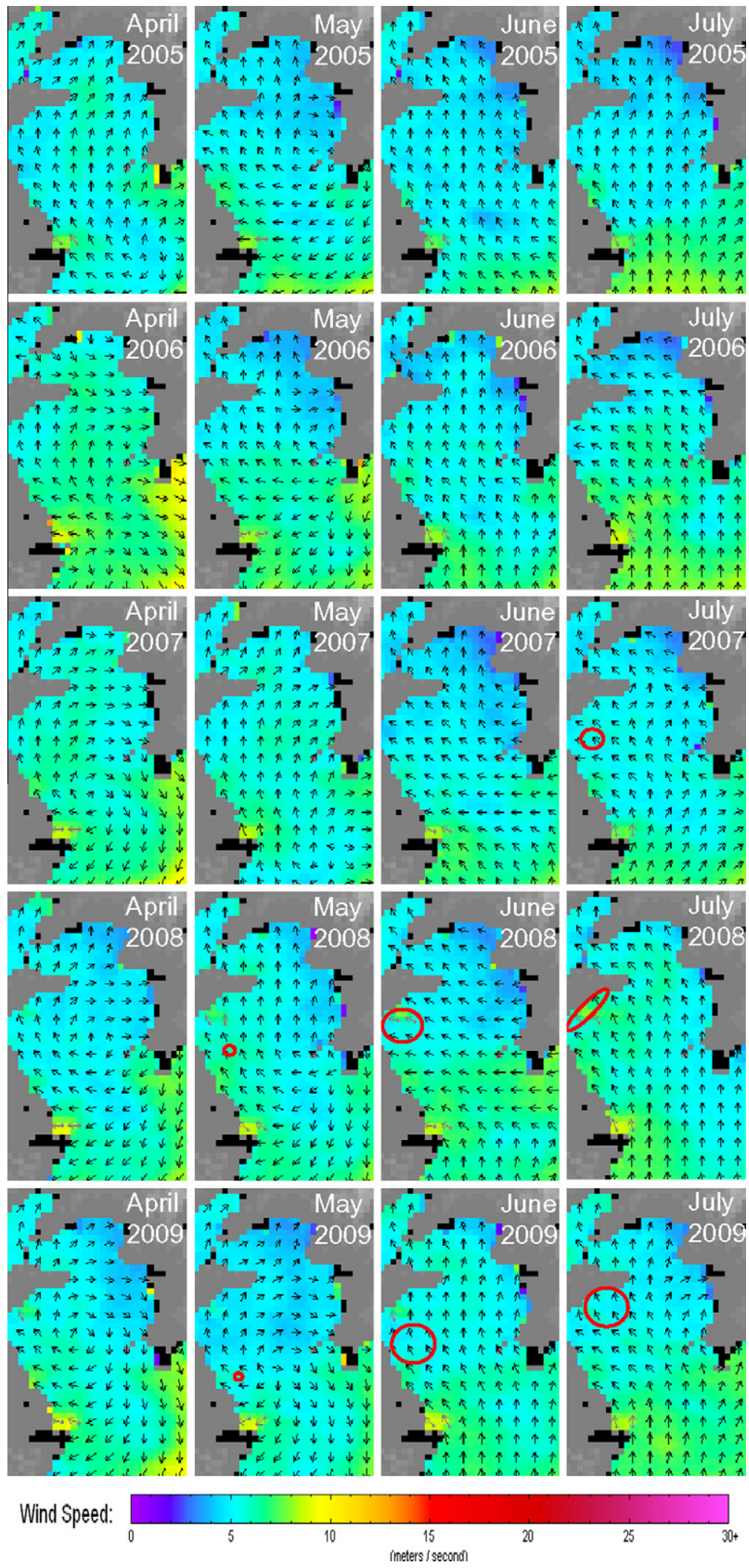

Fig. 6. Monthly averaged surface wind speed and direction in April, May, June and July from 2005 to 2009. Red circles indicate extent of patches of floating algae for 17 July 2007, 14 May 2008, 15 June 2008, 17 July 2008, 26 May 2009, 14 June 2009 and 15 July 2009.

If we examine images from the 2009 bloom that area of a similar size and location to that in mid May 2008 (e.g., 11 June 2009, see Fig. 4) and knowing the ontology of the 2009 bloom and the wind speed and direction in May 2008, we can calculate that the 2008 bloom is very likely to have originated in a similar location to the 2009 bloom. 

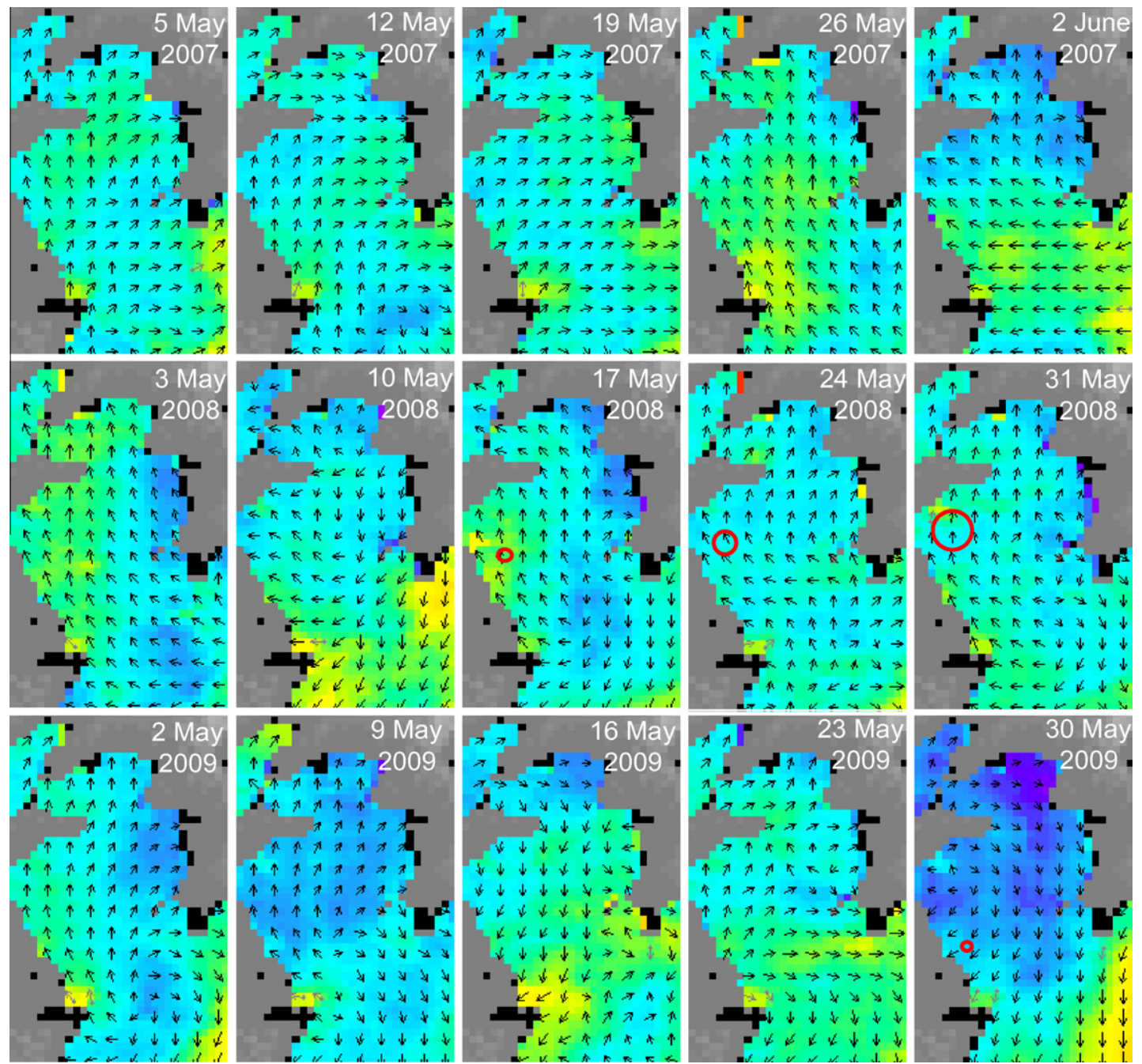

Fig. 7a. Weekly averaged surface wind speed and direction from May in 2007 to 2009. The date shown in each panel is the last day of the week averaged. The wind speed legend is the same as in Fig. 6. Red circles indicate extent of patches of floating algae for 14, 20, 30 May 2008; 26 May 2009.

Only one image of the 2007 bloom (July 17, see Fig. 2) was obtained. At that time, it was located over $100 \mathrm{~km}$ off the coast and to the north of Lianyungang, covering more than $82 \mathrm{~km}^{2}$ (Table 1). Little can be deduced of its origin except that its similarity to the blooms in 2008 and 2009 and given the prevailing pattern of winds from the south in June and July 2007 (Fig. 7b and c), it is also possible that the 2007 bloom had the same ontology as the 2008 and 2009 blooms.

This location to which we tracked the origin of the 2009 bloom (and probably those in 2007 and 2008) is immediately offshore of an area used intensively for Porphyra aquaculture (Fig. 8a). Dense lines of aquaculture rafts can be seen all along the coast in this region (pers. obs.) and offshore to at least $12 \mathrm{~km}$ (e.g., see $32^{\circ} 34^{\prime} 25.07^{\prime \prime} \mathrm{N}$ and $121^{\circ} 16^{\prime} 06.49^{\prime \prime} \mathrm{E}$ on Google Earth) on intertidal sand flats and ridges. There has been a recent threefold or over $200 \%$ expansion in the area of the intertidal coastline used for Porphyra aquaculture from 9400 to 28,500 ha between 2004 and 2008 (Fig. 9). It can be seen that over this period Porphyra aquaculture in the Lianyungang region grew by $158 \%$ from 2633 to 6800 ha and by $138 \%$ from 5600 to 13,333 ha in the Nantong area. However, in the Yancheng area, the Porphyra aquaculture area grew by $610 \%$ from 1173 to 8333 ha over the same period.

\section{Discussion}

4.1. Inter-annual patterns and novelty of macroalgal blooms in the Yellow Sea

In this study, we found no evidence of floating algae between 2004 and 2006 inclusive. A small bloom $\left(82 \mathrm{~km}^{2}\right)$ was found in 2007 compared with large blooms of $3489 \mathrm{~km}^{2}$ in 2008 and $4994 \mathrm{~km}^{2}$ in 2009. These observations are consistent with the scale of the resultant green-tides from these events. In 2007, 6000 tonnes of $U$. prolifera were cleaned up from the coastline near to Qingdao in August ( $\mathrm{Li}$ et al., 2009) while in 2008 it was well documented that about 1 million tonnes was cleaned up in and around Qingdao (e.g., Liu et al., 2009). The 2009 green-tide was more widespread along the Shandong Peninsula (Liu et al., 2010a; Shandong News 13 June, 2009). From these data we can conclude with confidence that the large-scale blooms in 2008 and 2009, the worlds two largest, are novel events. The occurrence of a smaller bloom in 2007 is suggestive that the factor(s) responsible for either the bloom initiation or the mechanism(s) of its growth were present or at least partially active in 2007 . Using similar methods, Hu et al. (2010) also found evidence of floating algae in the Yellow Sea between 2007 and 2009 but not before. They did 

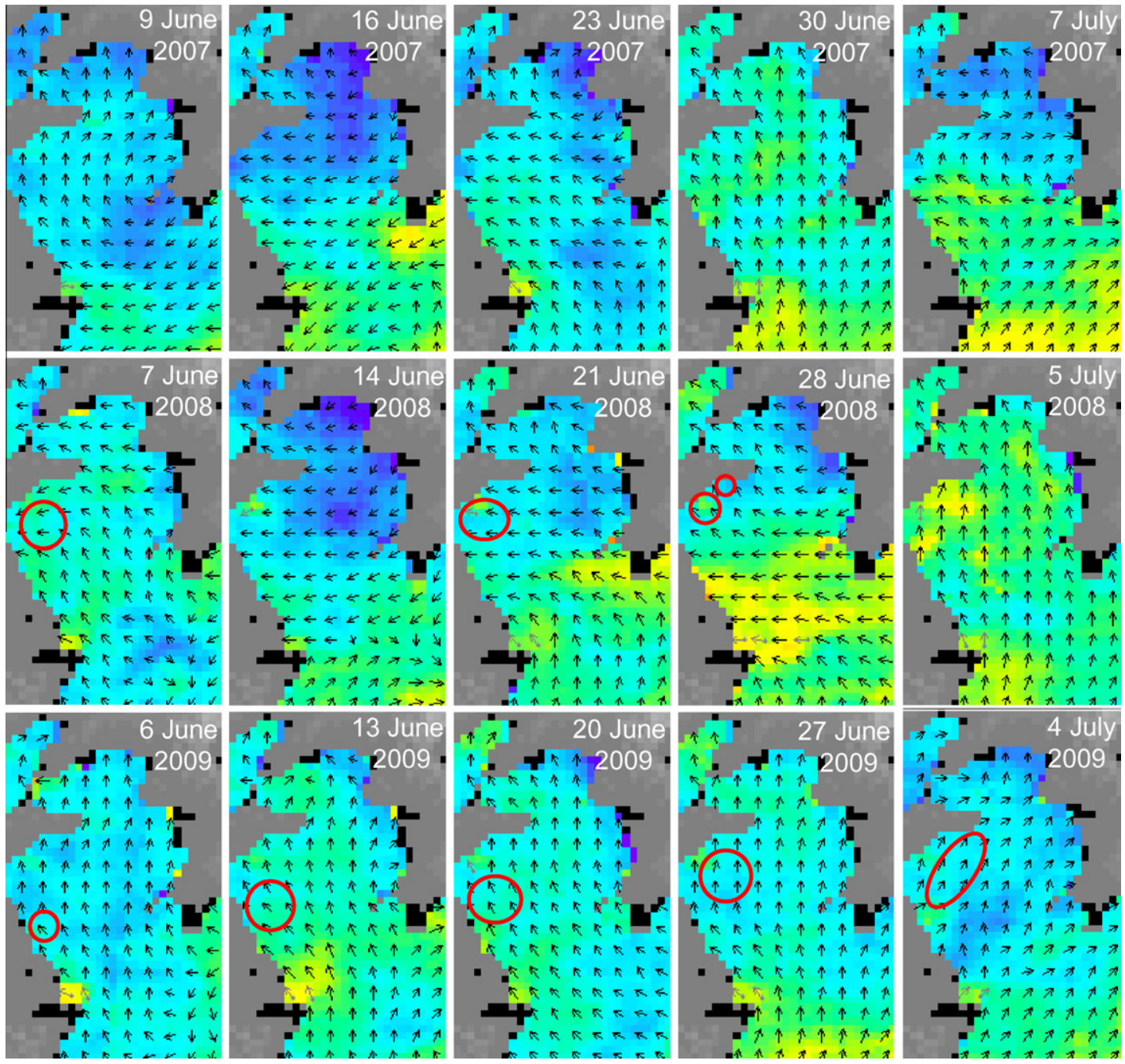

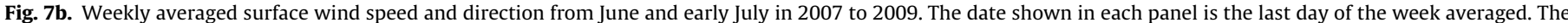
wind speed legend is the same as in Fig. 6 . Red circles indicate extent of patches of floating algae for 6, 15, 28 June 2008; 3, $11,14,23$ June $2009 ; 1$ July 2009.

however find evidence of blooms which could have been green macroalgae in the East China Sea prior to 2006 but these were negligible in size. The largest bloom they found in the East China Sea was in 2008 and they attributed this to being U. prolifera and having the same source as the 2008 Yellow Sea bloom (Porphyra aquaculture on the "Subei" Bank).

Next, we examined whether there was any inter-annual patterns in oceanographic conditions that could help explain the novelty of these blooms. Sea surface temperature (SST) and wind patterns showed a high level of consistency from 2005 to 2009 following the typical summer pattern for this region which is characterized by northward wind driven currents (Naimie et al., 2001; Liu and $\mathrm{Hu}, 2009$ ). Thus, there was no change in oceanographic temperature and wind patterns that could explain the novelty of the blooms. From 2005 to 2009 only minor variations around the typical summer pattern were evident and these are discussed below.

\subsection{Intra-annual patterns}

While inter-annual variability in oceanographic patterns cannot explain the cause of blooms, they do explain the observed dynamics of the blooms in 2008 and 2009. In particular, intra-annual variability in winds explained the time course and patterns in the distribution and movement of floating algae and the resultant green tides in 2008 and 2009. The timing and location of when and where the green tide appeared on the shore matched media and published reports of the green tides, in particular the concentration of the 2008 green tide around Qingdao (Liu et al., 2009; Shi and Wang, 2009) and the more northerly and more widely dispersed green tide along the Shandong Peninsula in 2009 (Liu et al., 2010a). The relative scale of the green tides reported in 2007, 2008 and 2009 also matched our analysis of the scale and distribution of the blooms that preceded the green-tides in each of those years. The timing and location of the 2008 bloom in our study matched that in the analysis undertaken by Liu et al. (2009), Shi and Wang (2009) and Hu (2009). Our estimates of cover of floating algae $\left(3489 \mathrm{~km}^{2}\right)$ exceeds that calculated using NDVI by Liu et al. (2009) at the peak of the 2008 bloom $\left(1200 \mathrm{~km}^{2}\right)$, but are similar to that of $\mathrm{Hu}$ and $\mathrm{He}$ (2008) and Shi and Wang (2009) whose estimates were 4000 and $3800 \mathrm{~km}^{2}$, respectively.

\subsection{Origin and possible cause of blooms}

This study tracked the origin of the 2009 bloom to the Jiangsu province coastline near Nantong and Yancheng where there are large areas of intertidal sand flats and ridges extending many kilometers offshore (Fig. 8a). Other authors also concluded the coastal area of the south-west Yellow Sea was the origin of the 2008 bloom (e.g., Liu et al., 2009; Ding et al., 2009; Hu, 2009; Shi and Wang, 2009; Xu et al., 2009; Pang et al., 2010; Hu et al., 2010). However 

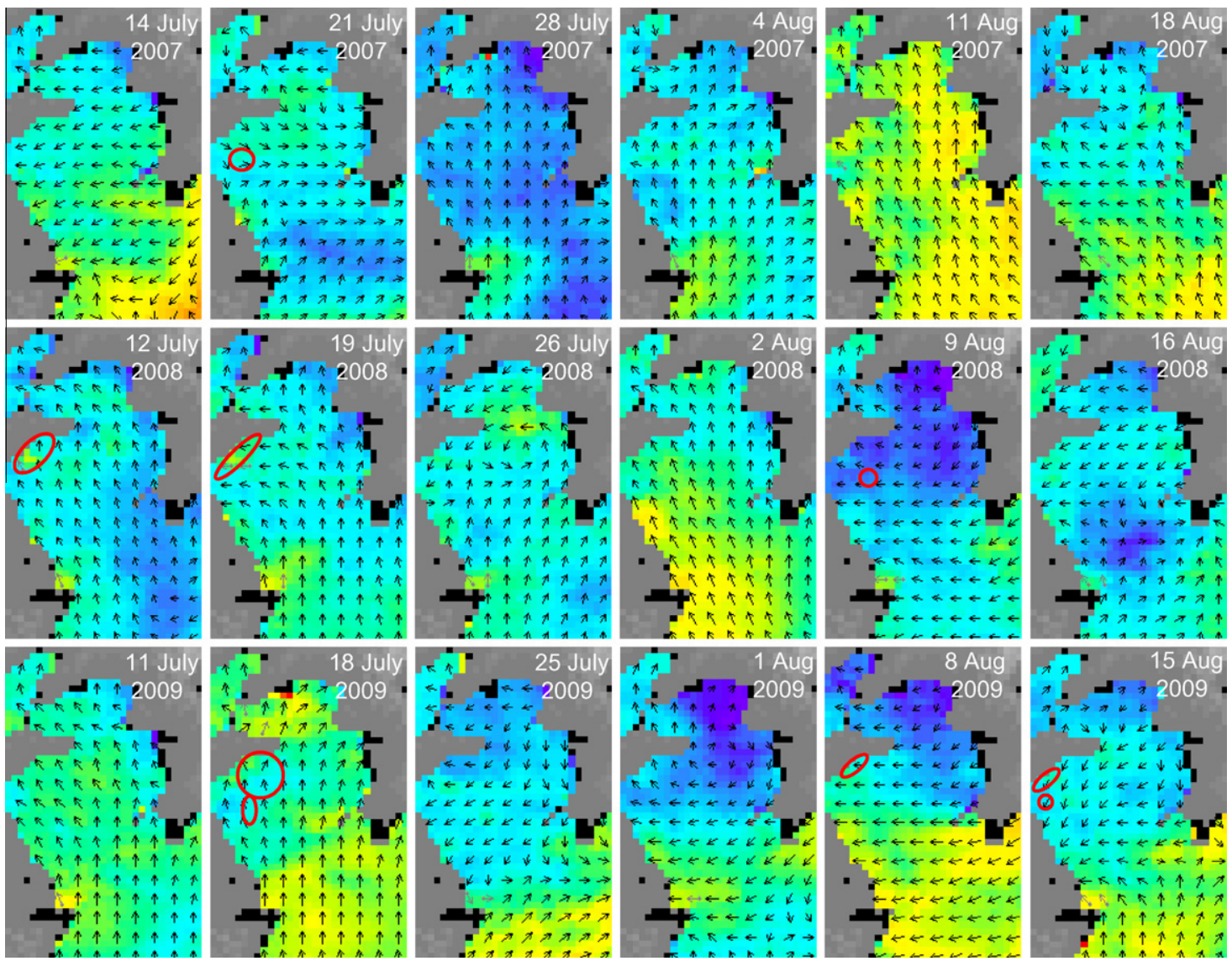

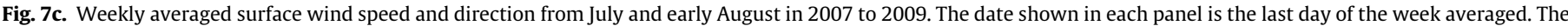

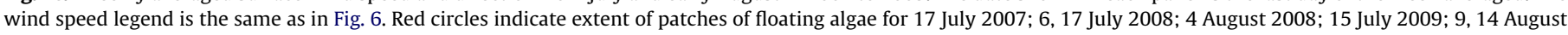
2009.

of these, only Liu et al. (2009), Hu et al. (2010) and Pang et al. (2010) pointed out specific source locations. Our results are coincident with the source nominated by Liu et al. (2009) and Hu et al. (2010), and indicate that the 2007, 2008 and 2009 blooms are likely to have originated from the same point source near Nantong and Yancheng.

Having ruled out unusual or novel oceanographic circumstances in 2008 and 2009, this study points to a novel or recently changed set of circumstances in this region of coastal Jiangsu province as being responsible for the source of the blooms. Here we proceed to assess the most likely cause of the blooms by reviewing previous studies in light of the findings in our study. Three points of origin and five mechanisms have been advanced thus far to explain the blooms.

Liu et al. (2009) proposed that the source of the blooms was the rapid expansion of Porphyra seaweed aquaculture along the Jiangsu province coast. They later demonstrated (Liu et al., 2010a) that very high biomass (ca. 5000 tonnes) of $U$. prolifera accumulated on the aquaculture rafts and that the genetic signature of this algae was an almost identical match to the $U$. prolifera which formed the 2008 Qingdao green-tide. This strain of $U$. prolifera is also not present in the coastal area of Qingdao at other times of the year (Liu et al., 2010b).

The location of origin determined in this study was within the more general area suggested by Liu et al. (2009). Our study points to the origin being from a section of the Jiangsu province coastline between Nantong and Yancheng. Further support for this area of origin comes from the observations of $\mathrm{Hu}$ (2009) and $\mathrm{Hu}$ et al. (2010) that small slicks of floating algae can be observed using LandSat in the region of coastal intertidal sand flats which he called
"Subei Bank" in most years between 2000 and 2009. This was the same region shown in Fig. 8a and c to where we tracked the origin of the 2009 bloom. This was also the area where extensive expansion of Porphyra seaweed aquaculture has occurred since 2003 (Fig. 9) giving further support to the hypothesis of Liu et al. (2009, 2010a) that the seed source for the 2008 and 2009 blooms was the disposal directly into the sea of waste $U$. prolifera which grows on the Porphyra aquaculture rafts. The timing of the first appearance of the blooms in May 2008 and 2009 found in this study (Figs. 3 and 4) also follows the timing of the harvest of Porphyra and removal of culture apparatus in April (Liu et al., 2010a). The daily tidal range in this region is up to $4 \mathrm{~m}$ in this area and tidal currents play an important role in the coastal Yellow Sea (Moon et al., 2009). Thus, tides are likely to play an important role in transporting the $U$. prolifera biomass offshore from this location into the Yellow Sea.

Pang et al. (2010) presented a contrary view to that of Liu et al. (2009), suggesting that the source of the blooms were microscopic germlings of $U$. prolifera produced in coastal aquaculture ponds used for crab and shrimp farming situated along the coast near Lianyungang (Fig. 8b) near to the area where the 2008 bloom was first observed on 14 May 2008 (Figs. 3 and 8b). However, our study shows the 2008 bloom was larger and probably older than the 2009 bloom when it was first observed, $170 \mathrm{~km}$ to the south (Fig. 8a-c). The winds for the 2 weeks prior to our first observation in 2008 (14 May) were from the south-east (Fig. 7a) meaning the movement of algae during that period if present would have been from the same area where we observed the origin of the 2009 bloom. This finding suggests that the 2008 bloom began well south of the aquaculture ponds suggested as the source by 


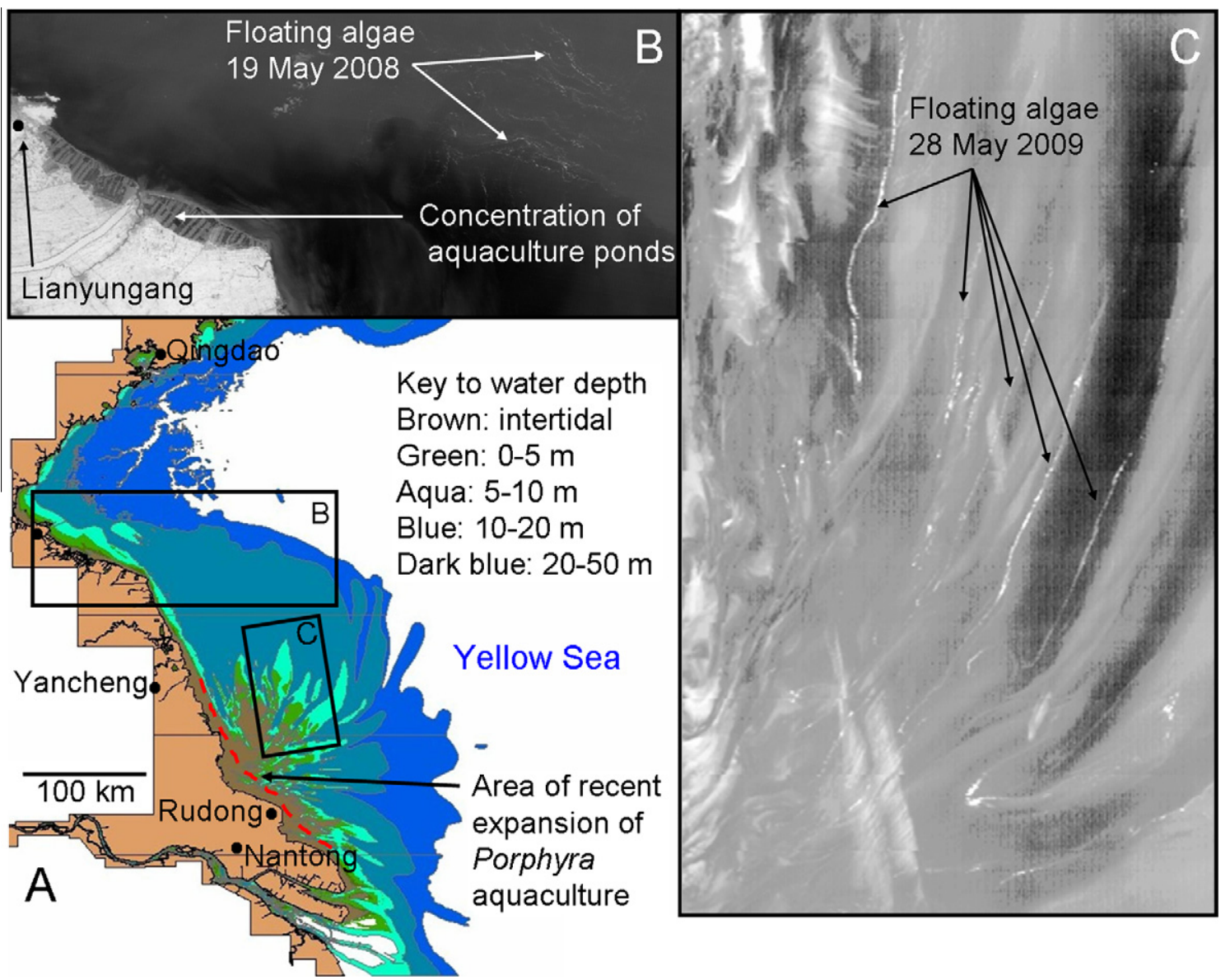

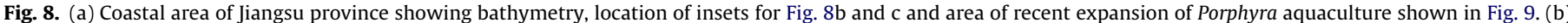

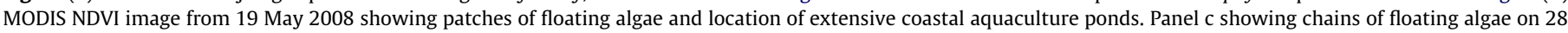
May 2009. Latitude and longitude for the central regions of floating algae in (b) and (c) are given in the text.

Pang et al. (2010) and pictured in Fig. 8b. The other factors which weigh against the aquaculture pond hypothesis advanced by Pang et al. (2010) is that the 2008 and 2009 blooms demonstrated a clear episodic dynamic (clear start and finish time). This is suggestive of point source inoculation over a limited time frame, rather than a continuous "drip feed" source of inoculant (which would be expected if the source was a continuous flow from ponds). In addition, the ponds are not novel phenomena unlike the recent expansion of Porphyra farming described by Liu et al. (2009) and illustrated here in Fig. 9. It is possible however that the source of $U$. prolifera germlings discovered by Pang et al. (2010) could contribute to the source of germlings that foul Porphyra rafts and give rise to the biomass accumulation. Porphyra aquaculture is also practiced nearby to the area of these aquaculture ponds south of Lianyungang.

Xu et al. (2009) described the 2008 bloom and the same patterns of movement and growth of the bloom as Liu et al. (2009), $\mathrm{Hu}$ (2009) and Shi and Wang (2009), but they attribute the source biomass for the bloom to the Yangtze River mouth and cite changed conditions since 2008 which they claim favor the growth of Enteromorpha (Ulva) in that estuary, rather than red-tide forming dinoflagellates which have historically been more prevalent. As with the hypothesis of Pang et al. (2010), although this source locality proposed by Xu et al. (2009) cannot be ruled out as a contributory source of $U$. prolifera germlings, it does not match the location of origin of the 2009 bloom so is discounted as being the primary source for the Yellow Sea blooms. Hu et al. (2010) used remote sensing methods to locate patches of floating algae in the
East China Sea, south-east of our study area, however they show these are more likely to have originated from the same coastal source ("Subei" Bank) as the Yellow Sea blooms than from the Yangtze River. This casts further doubt on the hypothesis for a Yangtze River source as advanced by Xu et al. (2009).

Presenting a fourth hypothesis, Zhang et al. (2010) claimed that somatic cells of $U$. prolifera can overwinter in sediments in the Yellow Sea and this could explain annual spring blooms. While so-

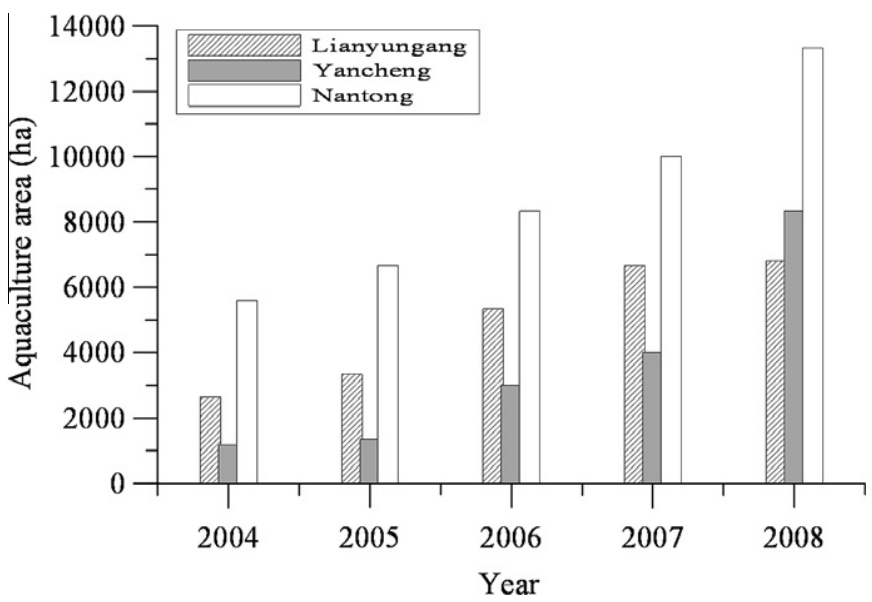

Fig. 9. Area under use for Porphyra aquaculture in three parts of the Jiangsu province coastline. Source: Jiangsu Ocean and Fisheries Bureau, www.jsof.gov.cn. 
matic cells resuspended from sediment may contribute to the blooms by attaching and germinating on substrates in the coastal zone, the absence of blooms prior to 2007 cast doubt on the mechanism proposed by Zhang et al. (2010) being the primary cause. In addition, their hypothesis does not explain the reason for the location of the origin of the blooms in 2008 and 2009.

The fifth putative cause of the blooms has been a general attribution to eutrophication (e.g., Leliaert et al., 2009) or enhanced nutrient supply from increased rainfall (Zhang et al., 2009). Enteromorpha (Ulva) species have been shown to have a high nitrogen requirement for optimal growth (Poole and Raven, 1997). The levels of nutrients in the Yellow Sea will be important for nourishing the rapidly expanding blooms and there is clear evidence of significant coastal eutrophication in parts of the Yellow Sea, especially near the mouth of the Yangtze River (e.g., Wang et al., 2003) which is to the south of the area where we found the blooms are initiated (Fig. 8). Thus, the same northward flowing wind driven currents responsible for moving the algal blooms would also transport these nutrients northwards to the area where the blooms were initiated. However, official monitoring of nutrients in the Yellow Sea by the State Oceanic Administration (SOA, 2009, Fig. 10) shows that dissolved inorganic nitrogen (DIN) in more than $50 \%$ of the areas sampled exceeded $14 \mu \mathrm{M}$ since 2003. Wang et al. (2003) measured nutrient levels in the Yellow Sea north of the Yangtze River mouth between 1997 and 1999 and found levels of $1-15 \mu \mathrm{M} \mathrm{l}^{-1}$ DIN. In areas of the northern Yellow Sea away from the shore that are of interest in our paper, Wang et al. (2003) found levels of 1-4 $\mathrm{MM}$ DIN. Fu et al. (2009) found similar patterns in 2006 and 2007. All this suggests that eutrophication of the Yellow Sea, in particular the coastal areas, pre-dates any of the 2007-2009 U. prolifera blooms.

Detached algae, which form floating blooms, can be very efficient at extracting nutrients even at low levels (e.g., Lovelock et al., 2008). Li et al. (2009) showed that detached U. prolifera thalli collected from the 2008 Qingdao green tide continued to add biomass (grow) at $3.85 \%$ per day without the addition of nutrients (5.4 $\mu \mathrm{M}$ DIN) at $20^{\circ} \mathrm{C}$. They found that adding 10 and $50 \mu \mathrm{M}$ of DIN increased biomass to $6.31 \%$ and $6.32 \%$ per day, respectively. The optimal growth of the closely related $U$. linza occurred at $14 \mu \mathrm{M}$ DIN with growth inhibited at $21 \mu \mathrm{M}$ DIN (Berglund, 1969).

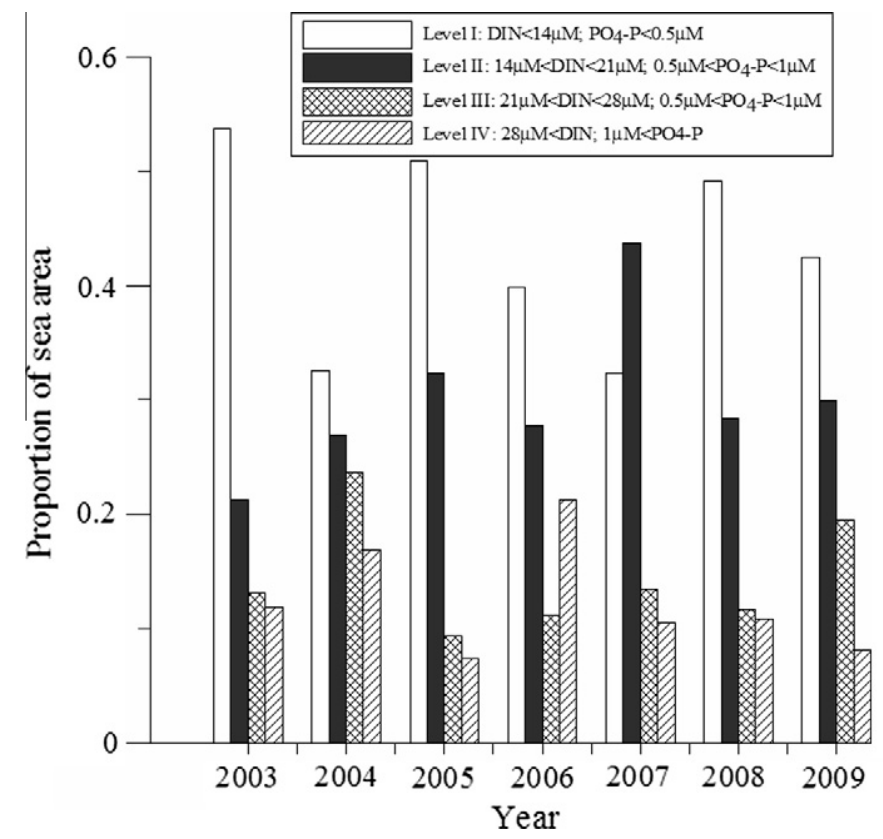

Fig. 10. Yellow Sea nutrient monitoring data from 2003 to 2009. Source: SOA (2009).
Clearly enhanced levels of bioavailable nutrients are a prerequisite for bloom formation and while recent increases in the level of eutrophication of the Yellow Sea cannot be ruled out and if present, would certainly contribute to the severity of blooms, those advancing this hypothesis as causing the blooms have failed to demonstrate that there has been a significant and recent change to the levels of eutrophication to the extent that would explain the novelty of the 2008 and 2009 U. prolifera blooms. Secondly, regardless of nutrient levels, a source of seed biomass is a prerequisite for a bloom and at this stage; the most probable source is the waste $U$. prolifera, which accumulates on Porphyra aquaculture rafts. Even so, the role of nutrients in determining rates of near shore biomass accumulation of $U$. prolifera and growth rates during the floating phase of bloom formation and growth remains a poorly studied aspect of this phenomenon. Liu et al. (2007) showed that the biomass of attached benthic green algae including Enteromorpha (Ulva) species was enhanced where local point sources of pollution from sewage occurred in the Yellow Sea. Thus near shore eutrophic conditions caused by an expansion of point sources of nutrient pollution may act to enhance reproductive output (spore formation) of $U$. prolifera in coastal areas of north-eastern China potentially contributing to a worsening problem.

\section{Conclusion}

We have shown the scale of the 2008 and 2009 blooms to be novel events preceded by a much smaller bloom in 2007. There was no change in oceanographic features, when wind and SST patterns were analyzed, that could explain the novelty of the blooms. Indeed from 2005 to 2009 only minor variations around the typical summer pattern were evident. Those minor variations, in particular in wind patterns correlate well with the differential pattern of movement of the 2008 and 2009 blooms during their growth phase and period of deposition along the Shandong province coastline. The origin of the 2009 (and most likely the 2008 and 2007 blooms) was tracked to a location on the Chinese Jiangsu province coastline between Nantong and Yancheng where recent expansion of Porphyra aquaculture is likely to have provided the source biomass for the blooms. Other hypotheses of the source of the blooms are not consistent with the location of origin of the blooms, do not provide a mechanism consistent with the observed episodic nature of the blooms and/or fail to adequately define the source of the seed biomass for the bloom. Nevertheless, much remains to be done to explain all the related biogeochemical and physical dynamics that give rise to the blooms and in the mean time, the precautionary principle would suggest acting on the recommendation of Liu et al. (2009) to dispose of waste $U$. prolifera, from Porphyra aquaculture activities, on land rather than dumping into the sea would be a prudent precaution against future blooms.

\section{Acknowledgements}

We thank Dr. Ming Feng at CSIRO for helpful suggestions to the manuscript. The first author is grateful to Yajun Shi for his assistance during an excursion to examine field sites along the Jiangsu province coastline. This research was supported by funding from CSIRO's Wealth from Ocean's Flagship, the Australian Academy of Science and CAS Innovative Program (No. KZCX2-YW-Q07-04).

\section{References}

Berglund, H., 1969. On the cultivation of multicellular marine green algae in axenic culture. Svensk Bot. Tidskr. 63, 251-264.

Cormen, T.H., Leiserson, C.E., Rivest, R.L., Stein, C., 2001. Introduction to Algorithms, second ed. The MIT Press, Boston. 
Ding, L., Luan, S., 2009. The taxonomy, habit and distribution of a green alga Enteromorpha prolifera (Ulvales, Chlorophyta). Oceanol. Limnol. Sin. 40 (1), 6871 (in Chinese with English abstract).

Ding, L., Fei, X., Lu, Q., Deng, Y., Lian, S., 2009. The possibility analysis of habitats, origin and reappearance of bloom green alga (Enteromorpha prolifera) on inshore of western Yellow Sea. Chin. J. Oceanol. Limnol. 27 (3), 421-424. doi:10.1007/s00343-009-9277-x.

Fletcher, R.T., 1996. The occurrence of 'green-tide'. In: Schramm, W., Nienhuis, P.H. (Eds.), Marine Benthic Vegetation - Recent Changes and the Effects of Eutrophication. Springer Verlag, Berlin, pp. 7-43.

Fu, G., Yao, J., Liu, F., Liu, J., Wang, X., Fu, W., Li, D., Zhou, M., Song, S., Duan, D., 2008. Effect of temperature and irradiance on the growth and reproduction of Enteromorpha prolifera J. Ag. (Chlorophycophyta, Chlorophyceae). Chin. J. Oceanol. Limnol. 26 (4), 357-362.

Fu, M., Wang, Z., Li, Y., Li, R., Sun, P., Wei, X., Lin, X., Guo, J., 2009. Phytoplankton biomass size structure and its regulation in the Southern Yellow Sea (China): seasonal variability. Cont. Shelf Res. 29, 2178-2194.

Hayden, H.S., Blomster, J., Maggs, C.A., Silva, P.C., Stanhope, M.J., Waaland, J.R., 2003. Linnaeus was right all along: Ulva and Enteromorpha are not distinct genera. Eur. J. Phycol. 38, 277-294.

$\mathrm{Hu}, \mathrm{C} ., 2009$. A novel ocean color index to detect floating algae in the global oceans. Remote Sens. Environ. 113, 2118-2129.

Hu, C., He, M.-X., 2008. Origin and offshore extent of floating algae in Olympic sailing area. EOS Am. Geophys. Union Trans. 89 (33), 302-303.

Hu, C., Li, D., Chen, C., Ge, J., Muller-Karger, F.E., Liu, J., Yu, F., He, M.-X., 2010. On the recurrent Ulva prolifera blooms in the Yellow Sea and East China Sea. J. Geophys. Res. 115, 105017. doi:10.1029/2009JC005561.

Jiang, P., Wang, J.F., Cui, Y.L., Li, Y.X., Lin, H.Z., Qin, S., 2008. Molecular phylogenetic analysis of attached Ulvaceae species and free-floating Enteromorpha from Qingdao coasts in 2007. Chin. J. Oceanol. Limnol. 26 (3), 276-279.

Leliaert, F., Zhang, X., Ye, N., Malta, E., Engelen, A.H., Mineur, F., Verbruggen, H., De Clerck, O., 2009. Identity of the Qingdao algal bloom. Phycol. Res. 57, 147-151.

Li, R., Wu, X., Wei, Q., Wang, Z., Li, Y., Sun, P., 2009. Growth of Enteromorpha prolifera under different nutrient conditions. Adv. Mar. Sci. 27 (2), 211-216 (in Chinese with English abstract)

Liang, Z., Lin, X., Ma, M., Zhang, J., Yan, X., Liu, T., 2008. A preliminary study of the Enteromorpha prolifera drift gathering causing the green-tide phenomenon. Period. Ocean Univ. China 38 (4), 601-604 (in Chinese with English abstract).

Liu, Z., Hu, D., 2009. Preliminary study on the Huanghai Sea coastal current and its relationship with local wind in summer. Acta Oceanol. Sin. 31 (2), 1-7 (in Chinese).

Liu, D., Bai, J., Song, S., Zhang, J., Sun, P., Li, Y., Han, G., 2007. The impact of sewage discharge on the macroalgae community in the Yellow Sea coastal area around Qingdao, China. Water Air Soil Pollut.: Focus 7, 683-692. doi:10.1007/s11267007-9121-2

Liu, D., Keesing, J.K., Xing, Q., Shi, P., 2009. The world largest green-tide caused by Porphyra aquaculture. Mar. Pollut. Bull. 58, 888-895.

Liu, D., Keesing, J.K., Dong, Z., Zhen, Y., Di, B., Shi, Y., Fearns, P., Shi, P., 2010a. Recurrence of Yellow Sea green tide in June 2009 confirms coastal seaweed aquaculture provides nursery for generation of macroalgal blooms. Mar. Pollut. Bull. 60, 1423-1432.

Liu, F., Pang, S.J., Chopin, T., Xu, N., Shan, T.F., Gao, S.Q., Sun, S., 2010b. The dominant Ulva strain of the 2008 green alagal bloom in the Yellow Sea was not detected in the coastal waters of Qingdao in the following winter. J. Appl. Phycol. 22, 531540.

Lovelock, C.E., Clegg, E., Hurrey, L., Udy, J., Moore, K., 2008. Growth and physiology of nuisance alga Hincksia sordida during a bloom in South East Queensland, Australia. J. Exp. Mar. Biol. Ecol. 363, 84-88.

Moon, J.H., Hirose, N., Yoon, J.H., 2009. Comparison of wind and tidal contributions to seasonal circulation of the Yellow Sea. J. Geophys. Res. 114. doi:10.1029/ 2009JC005314.

Morand, P., Briand, X., 1996. Excessive growth of macroalgae: a symptom of environmental disturbance. Bot. Mar. 39, 491-516.

Naimie, C.E., Blain, C.A., Lynch, D.R., 2001. Seasonal mean circulation in the Yellow Sea - a model generated climatology. Cont. Shelf Res. 21, 667-695.

Pang, S.J., Liu, F., Shan, T.F., Xu, N., Zhang, Z.H., Gao, S.Q., Chopin, T., Sun, S., 2010 Tracking the algal origin of the Ulva bloom in the Yellow Sea by a combination of molecular, morphological and physiological analyses. Mar. Environ. Res. 69 (4), 207-215

Poole, L.J., Raven, J.A., 1997. The biology of Enteromorpha. In: Round, F.E., Chapman, D.J. (Eds.), Progress in Phycological Research, vol. 12. Biopress Ltd., p. 8.

Rouse Jr., J.W., Haas, R.H., Schell, J.A., Deering, D.W., 1974. Monitoring vegetation systems in the Great Plains with ERTS. In: NASA. Goddard Space Flight Center 3d ERTS-1 Symposium, vol. 1, Sect. A, pp. 309-317 (SEE N74-30705 20-13).

Shandong News 13 June 2009. News Report Based on Information from the State Oceanic Administration (SOA), P.R. China. Available from: <http:// www.sdnews.com.cn/news/2009/6/13/778484.html/>.

Shi, W., Wang, M., 2009. Green macroalgae blooms in the Yellow Sea during the spring and summer of 2008. J. Geophys. Res. 114, C120010. doi:10.1029/ 2009JC005513.

State Oceanic Administration People's Republic of China (SOA), 2009. Marine Environment Quality Status Quo of the National Sea Waters 2003, 2004, 2005 2006, 2007, 2008, 2009. Available from: <www.soa.gov.cn/>.

Wang, B., Wang, X., Zhan, R., 2003. Nutrient conditions in the Yellow Sea and the East China Sea. Estuarine Coastal Shelf Sci. 58, 127-136.

Wang, W., Wang, F, Chen, S., Sun, X, Wang, X, Xing, S, Wang, J., 2008, PCR amplification and sequence analysis of ITS regions of Enteromorpha prolifera. Mar. Fish. Res. 29 (5), 124-129 (in Chinese with English abstract).

Wang, J., Jiang, P., Cui, Y., Li, N., Wang, M., Lin, H., He, P., Qin, S., 2010. Molecular analysis of green-tide-forming macroalgae in the Yellow Sea. Aquat. Bot. 93, 25-31.

$\mathrm{Xu}, \mathrm{Z}$., Ye, S., Xu, R., 2009. Possible conditions and process of the massive blooms of Enteromorpha prolifera in China during 2008. J. Fish. China 33 (3), 430-437.

Zhang, X., Mao, Y., Zhuang, Z., Liu, S., Wang, Q., Ye, N., 2008. Morphological characteristics and molecular phylogenetic analysis of green tide Enteromorpha sp. occurred in the Yellow Sea. J. Fish. Sci. China 15 (5), 822-829 (in Chinese with English abstract).

Zhang, S.P., Liu, Y.C., Zhang, G.Q., Guan, L., 2009. Analysis on the hydrometeorological conditions from remote sensing data for the 2008 algal blooming in the Yellow Sea. Period. Ocean Univ. China 39 (5), 870-876 (in Chinese with English abstract).

Zhang, X., Wang, H., Mao, Y., Liang, C., Zhuang, Z., Wang, Q., Ye, N., 2010. Somatic cells serve as potential propagule bank of Enteromorpha prolifera forming green tide in the Yellow Sea, China. J. Appl. Phycol. 22, 173-180. 